\title{
O mundo dos fundos, ou quem eram os vizi- nhos dos engenhos de açúcar no Rio de Janeiro colonial? (freguesia de Campo Grande, Rio de Janeiro, 1777-1813)*
}

\section{The sugar mill's yard: who were the sugar mill's neighbors in colonial Rio de Janeiro? (Campo Grande civil parish, Brazil, 1777-1813)}

Resumo: O objetivo deste artigo é discernir o peso sócio-econômico de famílias de homens livres e pobres no seio de uma economia colonial, agroexportadora e escravista. Tentaremos demonstrar a importância do trabalho de sitiantes para a sobrevivência dos engenhos de açúcar cariocas, defendendo que havia uma grande diferenciação social ao redor de um engenho, mas que essa desigualdade não se desdobrava em segregação espacial.

Palavras-chave: homens livres pobres, engenhos de açúcar, economia escravista colonial.

*Os resultados discutidos neste artigo são provenientes de pesquisa financiada pelo CNPq e PDEE-CAPES, defendidos em 2008 como tese de doutorado. A redação e revisão do artigo foram possíveis durante estágio pós-doutoral no ano de 2009 na Universidade de Montréal, financiado pelo Ministério dos Assuntos Estrangeiros do Governo do Canadá. Agradecemos especialmente ao professor Christian Dessureault pela supervisão e pelo apoio, mas o texto final é de nossa inteira responsabilidade. Quaisquer críticas, sugestões ou comentários são bem vindos pelo e-mail manoelap@gmail.com.

**Bacharel, Licenciada e Mestre em História, Doutora em Ciências Sociais pela Unicamp Brasil e Pós-doutora em História pela Universidade de Montréal - Canadá. 
Abstract: The objective of this article is to discern the economic weight of free-men families in a colonial, exporter and slave economy. We will try to demonstrate the free families' importance for Carioca's sugar mills' survival, which defended strong social and economic differences. However, this inequality did not include spatial segregation.

Key-Words: poor free men, sugar mill, colonial slavery economy.

\section{Introdução}

Muito já foi pesquisado sobre a economia colonial escravista brasileira, incluindo o caso do Rio de Janeiro (Fragoso, 1996). No Recôncavo da Guanabara, que incluía a freguesia de Campo Grande, um grupo bastante restrito de homens se aproveitou de condições privilegiadas no campo da política - mercês, cargos, regalias, terras, monopólios - como base de seu enriquecimento e, posteriormente, converteu suas fortunas em empreendimentos açucareiros. (Fragoso, 2000) Esse processo se repetiu do século XVI até o esgotamento do ciclo do ouro, em meados do século XVIII, que iniciou a lenta decadência da produção canavieira no Recôncavo. Durante o século XIX, esta freguesia viveu relativo isolamento e estagnação econômica, pois outros passaram a ser os centros dinâmicos da produção agroexportadora do Rio de Janeiro. Para piorar, a baixa lucratividade de seus empreendimentos agrícolas aguçou localmente a crise de mãode-obra iniciada com o fim do tráfico negreiro, e quem sabe mesmo a tenha antecipado.

Mas olhando assim, de fora e de longe, tudo parece muito mais tranqüilo do que na experiência concreta dos atores que viveram essas dificuldades na pele. $\mathrm{O}$ problema é antigo na prática das ciências humanas, mas permanece candente: como relacionar escalas diferentes em que se passam os fenômenos sociais, sem confiar preguiçosamente na determinação completa de uma sobre outras? Nas palavras de Giovanni Levi, 
pode entender as ações de uma pessoa em suas concepções limitadas sem perder de vista as realidades globais que pesam em torno dela?" (Levi, 2003)

Fredrik Barth nos sugere que a ecologia é o cenário onde os atores agem (Barth, 2000). A partir de sua proposição, ao encararmos uma determinada estrutura social poderíamos continuamente nos perguntar: como os grupos em foco, sujeitos históricos portadores de valores e objetivos particulares, conseguiram construir com um mínimo de solidez a vida social local? Seguindo essa linha de raciocínio, acreditamos que determinadas paisagens agrárias podem ser encaradas como resultado de um processo 'aberto e fragmentado'.

Giovanni Levi atenta para o fato de que, no Antigo Regime, na falta de um mercado impessoal e autorregulado, os problemas de definição de preço e salários justos remetiam continuamente ao conceito de equidade. Nestes casos, se construiu um sistema de trocas em que os valores estão determinados pelas características daqueles que trocam, ao ponto do mesmo bem ter valores distintos conforme sejam as pessoas que entrem na transação. As medidas de valor assim geradas se tornam regras em sociedades equitativas e desiguais. Em países católicos, como em outras sociedades corporativas e hierarquizadas, a equidade é o critério de justiça distributiva, aquela que visa garantir a cada um o que o corresponde segundo seu estatuto social. A reciprocidade na desigualdade foi definida por Giovanni Levi como o conjunto de mecanismos de solidariedade que caracterizam um projeto social baseado na equidade, na analogia ou na justiça distributiva, e, ao mesmo tempo, na rígida hierarquização social. (Levi, 2002)

Por fim, reforçamos que metodologicamente este artigo lida com redes, famílias, estratégias e atores, tentando fugir do tipo de trabalho que prima pela quantificação e classificação que, usando as palavras de Levi, provocam sempre a sensação de demasiado impessoais e imprecisos (Levi, 1981).

Por isso gostaríamos de entrar nesses engenhos pelos fundos: nosso objeto são as famílias de sitiantes. Os chamamos de sitiantes porque assim se autodeclararam nas fontes que encontramos. Basi- 
camente, lidamos com a descendência dos lavradores brancos, pardos ou forros, que tinham seus sítios desde o século XVIII em regiões onde imperava a agricultura mercantil escravista, no caso, os engenhos de açúcar. Eles às vezes possuíam alguns escravos, mas quase nunca se tornaram senhores desses engenhos. Nossa questão principal é tentar discernir o peso sócio-econômico desses homens no seio de uma economia colonial, agroexportadora e escravista.

Nosso trabalho é bastante dificultado pelas fontes disponíveis, já que só alguns sitiantes foram listados nominalmente no Rol de Desobriga de 1813, e o original desse documento foi extraviado. Portanto, nos baseamos na transcrição feita por José Nazareth Fróes que, ao que parece, pôde contar com o documento original. (Fróes; Gelabert, 2004, p. 101-115) Também conseguimos rastrear alguns deles, e seus familiares, nos registros de batismo, casamento e óbito sistematizados pelo genealogista Carlos Rheigantz (1965). A aferição da capacidade produtiva de sitiantes e senhores de engenhos pode ser feita a partir da comparação entre os relatórios governamentais de 1777 e 1797 e esse Rol, segundo os cálculos e convenções que explicaremos a seguir ${ }^{1}$. Possuímos, além dessas fontes, apenas dois inventários de sitiantes, um falecido em 1797 e outro em $1819 .{ }^{2}$

Apesar dessas limitações, tentaremos demonstrar a importância de famílias de sitiantes para a economia de engenhos escravistas, defendendo duas hipóteses: primeiro, que havia uma clivagem social bem marcada não em torno da propriedade de escravos, nem das terras, mas em torno da propriedade de um engenho, mesmo que pequeno. Esse liame era o divisor de águas entre os senhores mais pobres e a ampla gama de sitiantes com até 15 escravos, e conferia aos primeiros status diferenciados destes últimos, mesmo que possuíssem igual ou até menor número de escravos. Nossa segunda hipótese é que, mesmo que a desigualdade econômica fosse grande e clara, com centenas de

\footnotetext{
${ }^{1} \mathrm{O}$ relatório feito pelos mestres de campo de 1777 também foi transcrito por Fróes (2004) e Affonso Várzea (1945), e o de 1797 por Alberto Lamego (1942).

${ }^{2}$ Arquivo Nacional. Fundo Inventários. Falecido: Manoel Roiz de Amorim. Apelação Cível de Anna Joaquina do Nascimento. Ano 1847. Notação 4116, caixa 3629. E Falecido: Miguel Cardoso Castel Branco. Ano 1797. Notação 8993.
} 
moradores com poucos escravos e poucos senhores com mais de meia centena de cativos, essas pessoas, bem ou mal, compartilhavam o mesmo espaço, desde o entorno do engenho até dentro da casa grande. $\mathrm{Ou}$ seja, a desigualdade econômica não se desdobrava em segregação espacial, com as conseqüências sociais e políticas advindas dessa convivência estreita entre mundos tão diferentes.

\section{Os engenhos de açúcar}

Discutiremos, nesta parte, a situação econômica dos engenhos de açúcar da freguesia de Campo Grande a partir de alguns relatórios e visitas feitos à época. Em 1769, o Marquês do Lavradio foi nomeado terceiro vice-rei da colônia, e empreendeu ao menos tentativas de gerenciar melhor a economia local. Para tanto, requereu de seus mestres-de-campo relatórios detalhados da situação dos engenhos de açúcar de seus distritos, no ano de 1777. Os mestres de campo listaram, então, os senhores e a condição de cada um desses engenhos, citando sua produtividade, o número de escravos e a qualidade da administração. Continuaremos conhecendo apenas os senhores de engenho, quedas de produtividade e sucessivas trocas patrimoniais, com o segundo relatório, elaborado em 1797. Os dois relatórios dos mestres-de-campo nos dão uma visão bem mais detalhada da situação dos engenhos de cana e seus senhores, permitindo vislumbrar algumas transformações entre 1777 e 1797. Mas os relatórios não pararam por aí. Em 1794, Monsenhor Pizarro, então Cônego da Sé, visitou a freguesia de Campo Grande. Depois de listar os senhores, Pizarro contabilizou as capelas existentes e, com elas, seus fundadores e administradores à época. Anos mais tarde, em 1813, um presbítero secular percorreu a freguesia e recenseou seus moradores, listagem que ficou registrada no Rol de Desobriga $n^{\circ} .15^{3}$.

\footnotetext{
${ }^{3}$ A Desobriga foi instituída no Brasil em 1717, e era "o instrumento legal de que os bispos dispunham para o levantamento populacional nas suas Dioceses". (Fróes; Gelabert, 2004, p. 101) A partir dos livros de Desobriga de 1788 a 1813, podemos inferir, por exemplo, o crescimento populacional da freguesia. Em 1788, havia 268 fogos e aproximadamente 2.235 pessoas na região. Em 1813, eram 432 fogos e 3.058 pessoas. Em 26 anos, houve aumento de $61 \%$ das residências e de $36 \%$ na população.
} 
Somando-se a esses "censos paroquais" os nomes dos senhores e a condição de seus engenhos fornecidos pelos primeiros relatórios, chegamos a um quadro da grande produção local, mesmo que ainda basicamente restrito aos senhores de engenho. Além disso, conseguimos entrever as principais transferências dos engenhos da freguesia entre 1777 e 1813, explicitando o vínculo, quando exposto, do dono com o seu antecessor. Tentamos sintetizar essas informações na tabela a seguir. ${ }^{4}$

Figura 1 - Tabela das Transmissões de Engenhos em Campo Grande $(1777-1813)$

\begin{tabular}{|c|c|c|c|c|}
\hline LOCAL / DATA & 1777 & 1794 & 1797 & 1813 \\
\hline BANGU & $\begin{array}{l}\text { Gregório de } \\
\text { Moraes Castro } \\
\text { Pimentel, } \\
\text { capitão* }\end{array}$ & $\begin{array}{l}\text { José Correia, } \\
\text { sargento-mor } \\
\text { (filho) }\end{array}$ & $\begin{array}{l}\text { Ana Bangu (filha } \\
\text { ou esposa) }\end{array}$ & $\begin{array}{l}\text { Manoel Joaquim } \\
\text { de Souza*, major } \\
\text { (inventariante) }\end{array}$ \\
\hline CABUÇU & $\begin{array}{l}\text { Úrsula Martins } \\
\text { (viúva de } \\
\text { Marcos Cardoso } \\
\text { dos Santos) }\end{array}$ & $\begin{array}{lr}\text { Úrsula } & \text { Martins } \\
\text { (viúva de } & \text { Marcos } \\
\text { Cardoso } & \text { dos } \\
\text { Santos) } & \end{array}$ & $\begin{array}{l}\text { José Cardoso dos } \\
\text { Santos (filho) }\end{array}$ & $\begin{array}{l}\text { Herdeiros de José } \\
\text { Cardoso dos } \\
\text { Santos }\end{array}$ \\
\hline CAMPINHO & & & $\begin{array}{l}\text { Francisco Pereira } \\
\text { Lemos, padre }\end{array}$ & $\begin{array}{l}\text { Francisco Pereira } \\
\text { Lemos, padre }\end{array}$ \\
\hline CAPOEIRAS & $\begin{array}{l}\text { Ana Maria de } \\
\text { Jesus (viúva de } \\
\text { João Pereira } \\
\text { Lemos) }\end{array}$ & 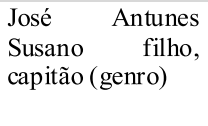 & $\begin{array}{l}\text { José } \quad \text { Antunes } \\
\text { Susanor filho, } \\
\text { capitão (genro) }\end{array}$ & 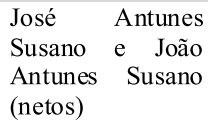 \\
\hline COQUEIROS & $\begin{array}{l}\text { José Antunes } \\
\text { Susano pai }\end{array}$ & $\begin{array}{l}\text { Vitória Barreto e } \\
\text { filhos (viúva de } \\
\text { José Antunes } \\
\text { Susano pai) }\end{array}$ & $\begin{array}{lr}\text { Manoel } & \text { Antunes } \\
\text { Susano, } & \text { alferes } \\
\text { (filho) } & \end{array}$ & $\begin{array}{lr}\text { Manoel } & \text { Antunes } \\
\text { Susano, } & \text { alferes } \\
\text { (filho) } & \end{array}$ \\
\hline GUANDU & $\begin{array}{l}\text { Francisco } \\
\text { Silva Sena }\end{array}$ & $\begin{array}{l}\text { Francisco } \\
\text { Silva Sena }\end{array}$ & $\begin{array}{l}\text { Francisco } \\
\text { Silva Sena }\end{array}$ & $\begin{array}{l}17 \text { pequenos } \\
\text { proprietários }\end{array}$ \\
\hline
\end{tabular}

\footnotetext{
${ }^{4}$ Como dissemos anteriormente, uma parte desses dados foi acessível apenas a partir de fontes secundárias, o que requereu mais cuidados e conferências quanto à correção da informação. Assim, usaremos em todo este trabalho o sinal * para explicitar uma informação que foi corrigida por nós, a partir da confrontação de uma fonte secundária com outras, e sobre a qual temos certeza da correção.
} 


\begin{tabular}{|c|c|c|c|c|}
\hline INHOAÍBA & $\begin{array}{l}\text { Antônio } \\
\text { Antunes } \\
\text { Susano* }\end{array}$ & $\begin{array}{lr}\text { José } & \text { Antunes } \\
\text { Susano } & \text { filho, } \\
\text { capitão } & \end{array}$ & $\begin{array}{l}\text { José Antunes } \\
\text { Susano (filho ou } \\
\text { neto?) }\end{array}$ & $\begin{array}{l}\text { José Antunes } \\
\text { Susano e Manoel } \\
\text { Antunes Susano }\end{array}$ \\
\hline JUARI & $\begin{array}{l}\text { Vitorino } \\
\text { Rodrigues } \\
\text { Rosas }\end{array}$ & $\begin{array}{l}\text { Bernardo José } \\
\begin{array}{l}\text { Dantas, tenente } \\
\text { (compra) }\end{array}\end{array}$ & $\begin{array}{l}\text { Bernardo José } \\
\text { Dantas, tenente }\end{array}$ & $\begin{array}{l}\text { Bernardo José } \\
\text { Dantas, tenente }\end{array}$ \\
\hline LAMARÃO & $\begin{array}{l}\text { Mariana Nunes } \\
\text { de Souza e } \\
\text { herdeiros }\end{array}$ & $\begin{array}{l}\text { José da Silva } \\
\text { Álvares, capitão }\end{array}$ & $\begin{array}{l}\text { José da Silva } \\
\text { Álvares, capitão }\end{array}$ & $\begin{array}{l}\text { José da Silva } \\
\text { Álvares, capitão }\end{array}$ \\
\hline $\begin{array}{l}\text { MATO DA } \\
\text { PACIÊNCIA }\end{array}$ & $\begin{array}{l}\text { João Carvalho } \\
\text { de Vasconcelos, } \\
\text { Cirurgião-mor }\end{array}$ & 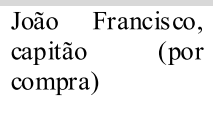 & $\begin{array}{l}\text { João Francisco, } \\
\text { negociante } \\
\text { (foreiro dos } \\
\text { carmelitas) }\end{array}$ & \\
\hline MENDANHA & $\begin{array}{l}\text { Francisco } \\
\text { Caetano de } \\
\text { Oliveira Braga, } \\
\text { capitão }\end{array}$ & $\begin{array}{l}\text { Antônio Couto da } \\
\text { Fonseca, padre } \\
\text { (compra) }\end{array}$ & $\begin{array}{l}\text { Antônio Couto da } \\
\text { Fonseca e José } \\
\text { Álvares } \\
\text { Azevedo }\end{array}$ & $\begin{array}{lr}\text { Antônio } & \text { Garcia } \\
\text { Durão } & \text { (herdeiro } \\
\text { de } & \text { Francisco } \\
\text { Garcia } & \text { do } \\
\text { Amaral) } & \end{array}$ \\
\hline PIRAQUARA & & $\begin{array}{l}\text { Maria Inácia } \\
\text { (viúva de Manoel } \\
\text { Fernandes } \\
\text { Barata) }\end{array}$ & $\begin{array}{l}\text { Maria Inácia } \\
\text { (viúva de Manoel } \\
\text { Fernandes } \\
\text { Barata) }\end{array}$ & $\begin{array}{l}\text { João e Sebastião } \\
\text { Fernandes Barata, } \\
\text { tenente }\end{array}$ \\
\hline RETIRO & & $\begin{array}{l}\text { José Correia, } \\
\text { sargento-mor }\end{array}$ & Ana Bangu & $\begin{array}{l}\text { Emerenciana } \\
\text { Maria }\end{array}$ \\
\hline $\begin{array}{l}\text { Rio da Prata do } \\
\text { CABUÇU }\end{array}$ & & $\begin{array}{l}\text { Marcos Cardoso } \\
\text { dos Santos (filho) }\end{array}$ & $\begin{array}{l}\text { Marcos Cardoso } \\
\text { dos Santos (filho) }\end{array}$ & $\begin{array}{lr}\text { Marcos } & \text { Cardoso } \\
\text { dos } & \text { Santos } \\
\text { (filho)* } & \end{array}$ \\
\hline TINGUI & & & & $\begin{array}{l}\text { Joaquim Pereira } \\
\text { de Lemos }\end{array}$ \\
\hline VIEGAS & $\begin{array}{l}\text { Manoel Freire } \\
\text { Ribeiro } \\
\text { (compra) }\end{array}$ & $\begin{array}{l}\text { Jerônimo } \\
\text { Ribeiro }\end{array}$ & $\begin{array}{l}\text { Francisco Garcia } \\
\text { do Amaral }\end{array}$ & $\begin{array}{l}\text { Manoel Antunes } \\
\text { Susano, alferes* }\end{array}$ \\
\hline
\end{tabular}

Fontes: Relatórios de 1777 e 1797, Visita Paroquial de 1794 e Desobriga de 1813.

Embora a crise econômica não seja delatada pelas fontes oficiais, ela era sentida por todos, mesmo que diferencialmente. Não se instalaram novos engenhos depois de 1794, sinal de que o período de colonização de Campo Grande com o objetivo de produzir açúcar já havia se esgotado. Outros engenhos ou deixaram de funcionar (como 
o de Guandu), ou trocaram muitas vezes de dono (caso de Viegas e Bangu) ou foram convertidos em engenhocas de aguardente, de fabrico mais simples e menos custoso. A reconversão da produção de açúcar para aguardente ou rapadura foi um sinal de que cada vez menos capital podia ser investido pelos senhores locais em suas fábricas.

Mas, embora todos esses fatores sejam indicativos das vicissitudes dos grandes circuitos de produção e acumulação, apenas tangenciam as questões que gostaríamos de abordar, quais sejam, as relações entre dois grupos distintos - senhores e moradores - e suas implicações em termos da economia e estrutura fundiária locais. Pudemos apenas inferir a permanência de sitiantes nas terras dos senhores por alguns registros de casamento (que explicitaram a naturalidade dos cônjuges) e por alguns inventários, mas uma caracterização geral só foi possível pela lista de 1813. Graças a ela pudemos ter noção de quantas famílias viviam efetivamente ao lado dos senhores de engenho, seus nomes e quantos escravos possuíam. Finalmente, tivemos ao menos uma fresta do que buscávamos. 


\section{O mundo dos fundos}

Figura 2 - Senhores e Sitiantes da Freguesia de Campo Grande em 1813.
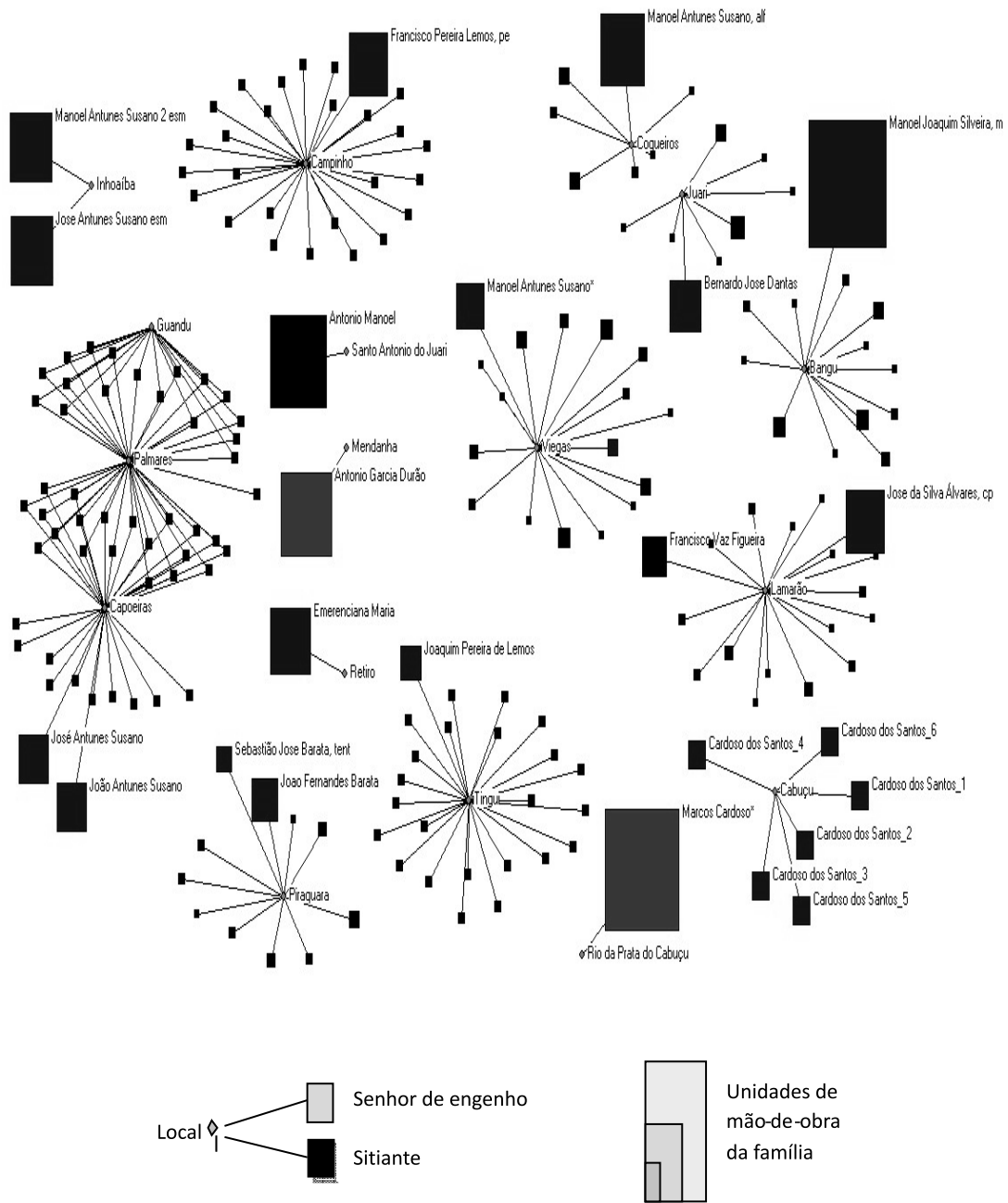

da família

Fonte: Desobriga de 1813.

Tentamos sintetizar os dados de 1813 num gráfico de rede que, mesmo com suas limitações, pode dar uma idéia da enorme complexidade sócio-econômica do local. Antes, faremos algumas observa- 
ções sobre a construção desse gráfico. O tamanho do quadrado representa o conjunto da mão-de-obra disponível para cada unidade produtiva, e sua aferição dá margem para debatermos uma questão teórico-metodológica importante: pesquisas sobre a produção canavieira no século XVII relacionam a baixa quantidade de escravos do senhor de engenho com o fato da produção da cana estar, nesse século, sob a responsabilidade dos lavradores livres. (Costa, 1988, p. 113; Fragoso, 2002, p. 9; Sampaio, 2003, p. 98-99) Nesse contexto, a quantidade de agregados que moravam em terras de um senhor, a diversidade dos tamanhos das famílias e as muitas famílias com poucos escravos, algumas com agregados, podem ser indicativos de uma miríade de fontes de mão-de-obra que não quisemos desconsiderar. Por isso, gostaríamos de medir a capacidade produtiva de cada sítio ou engenho em termos de Unidades de Mão-de-Obra (doravante UMO), mais pertinente do que a mera soma de seus escravos. Para chegarmos a esse número, foram somados o número de indivíduos de cada fogo, incluindo nele os membros da família nuclear (todos: marido, esposa e filhos, já que não tínhamos a informação da idade de cada um), o número de agregados, quando havia, e o número de escravos, também quando havia.

No caso dos senhores de engenhos de açúcar, os relatórios governamentais e a Desobriga nos fornecem o número de membros da família, de escravos e de agregados. Já no caso da maioria das unidades produtivas menores, que julgamos ser de sitiantes vizinhos aos engenhos, elas não tiveram seus membros nem escravos contabilizados (caso de vários fogos de Capoeiras e a totalidade de Campinho, Tingüi e Palmares), por isso, foi arbitrada por nós uma média de quatro UMO por fogo, que, mesmo encobrindo a diversidade, não deve estar longe de uma média regional.

Além disso, na Desobriga o pároco citou o chefe do fogo, nominalmente, e em seguida outros membros da unidade doméstica, nominalmente ou não, separados nas categorias de mulher, filho(a) e família e, por último, apenas o número total de agregados e escravos. Na categoria família, entendemos que o pároco citava membros da parentela, ascendentes ou colaterais, que moravam na mesma casa do chefe, so- 
mando, portanto, bocas e braços a essa unidade. Esse conjunto de pessoas, recenseado no mesmo fogo, para nós representaria uma maior ou menor unidade de produção e consumo, nos termos de Chayanov, conforme sua capacidade produtiva medida em UMOs. (Chayanov, 1966)

A situação dos agregados também merece alguma menção. $\mathrm{O}$ presbítero contabilizou 3 em torno do fogo de Mariano Carneiro, 52 em torno do fogo de José Antunes Susano, ambos em Inhoaíba; 12 em Cabuçu, 45 em Santo Antônio do Juari e 32 no Rio da Prata do Cabuçu. Apenas nestes exemplos contabilizamos $(3+52+12+45+32=144) 144$ famílias de agregados que, conforme convenções explicitadas anteriormente $(144 \times 4=576)$ totalizariam 576 UMO. Fizemos a opção metodológica de somar o número de agregados à capacidade produtiva deste fogo, entendendo por unidade produtiva algo mais amplo que unidade doméstica. Essa opção se deu baseada no fato de esses agregados não terem sido citados como chefes de fogos distintos, como tantos outros chefes de famílias pequenas, sem engenho e sem escravos; porque nunca possuíam escravos; porque em sua grande maioria foram arranchados em fogos pertencentes a um engenho; e, por último, porque o próprio pároco os distinguiu tanto desses fogos pequenos quanto de sitiantes ou escravos. Assim, embora não fique clara para nós a exata relação mantida entre o agregado e o senhor de engenho, que precisaria ser deslindada em outras fontes que não possuímos, parece que, pelos olhos da época, os agregados consistiam num grupo social distinto tanto da parentela, quanto da escravaria e dos sitiantes.

Além disso, se entendermos que não seja coincidência o fato de esses agregados estarem presentes em maior número justamente em torno de engenhos de açúcar, podemos nos indagar sobre o papel da proximidade do engenho na subsunção formal da força de trabalho livre existente, caracterizando-o por uma tradicional 'fome de cana' ou 'fome de braços' que, somada às prerrogativas políticas, militares, fundiárias e financeiras de seu senhor, faria com que essas fábricas pudessem contar com uma mão-de-obra potencial, distinta dos cativos mas de alguma forma dependente da casa-grande. Como se construíram e em que consistiriam esses laços de dependência é 
uma questão importantíssima que, infelizmente, não teremos condição de tratar neste artigo.

Por fim, o comprimento dos traços e a posição dos pontos no conjunto são arbitrários. Como se pode perceber, recorremos a uma série de procedimentos técnicos que visaram a sanar lacunas da documentação, cuja explicitação aqui serve para que possam ser contestados por outros especialistas.

O resultado, com aparência de réveillon, está na figura 2, que deve ser lida da seguinte maneira: os pólos agregadores são os locais em que o padre chegava e no qual recenseava seus moradores. Não são fazendas delimitadas, e nem havia cercas dividindo esses logradouros entre si. Nesses locais, cada fogo foi representado por um quadrado. Se os fogos correspondiam aos dos senhores de engenho, foram marcados em cinza; se não, foram deixados em preto.

A Desobriga de 1813 confirmou a existência de senhores de engenho com grande número de escravos e nenhum sitiante em suas terras, como Marcos Cardoso dos Santos, no Rio da Prata do Cabuçu, e Antônio Garcia Durão, no Mendanha (respectivamente com 124 e 83 $\mathrm{UMO}$ ). Atentamos para a evidência da riqueza dos senhores de engenho, em relação aos moradores, reflexo de sua inserção nos circuitos da agroexportação com maiores possibilidade de acumulação, evidenciado pelo maior número de escravos em relação aos não-senhores. Como prova, no espectro dos proprietários com mais UMO, encontramos apenas um único sitiante que não era senhor de engenho. No espectro dos que possuíam entre 15 e 50 cativos, também encontramos, além de vários senhores, apenas um morador: Francisco Vaz Figueira. Por último, no espectro dos que possuíam até 15 escravos havia apenas sitiantes.

Pela Desobriga de 1813 também pudemos confirmar a existência de centenas de sitiantes nas franjas dos engenhos da freguesia. Além das fazendas dos Cardoso dos Santos, Fernandes Barata, Antunes Susano e Dantas, havia ainda, na vizinhança, 38 famílias de pequenos sitiantes na Fazenda Palmares, 26 famílias na região de Campinho, e 20 na Fazenda Viegas. O problema é que, para conhecer melhor essas pessoas, se colocam as dificuldades de uma 'história vista de baixo': a falta de fontes produzidas pelos homens livres mais 
pobres. Como já dissemos, antes da Desobriga de 1813, as informações que possuímos são pontuais e muito fragmentárias. Essas famílias raramente deixaram inventários de seus bens, não abriram processos e não declararam a origem de suas terras, ao menos até 1854 .

\section{A economia dos fundos}

Para clarificar essa discussão em termos econômicos, e ao mesmo tempo dar conta de algumas transformações no tempo, confeccionamos o gráfico de mão-de-obra (figura 3), onde comparamos os escravos dos senhores em 1777 com as suas unidades de mão-de-obra em 1813 e, finalmente, com o somatório das UMO dos moradores do mesmo local, no mesmo ano de 1813. Novamente, tivemos de lidar com os dados incompletos de que dispúnhamos nos relatórios. O relatório de 1797 não precisou o número de escravos dos senhores. Para compor as UMO dos senhores em 1777, foi transladado apenas o número de escravos que constava neste relatório, já que este não forneceu informações sobre membros da família e agregados. Já para o ano de 1813, compusemos as UMO tanto dos senhores quanto dos sitiantes somando família, escravos e agregados.

Figura 3 - Gráfico da Mão-de-Obra Comparada em Campo Grande (1777-1813)

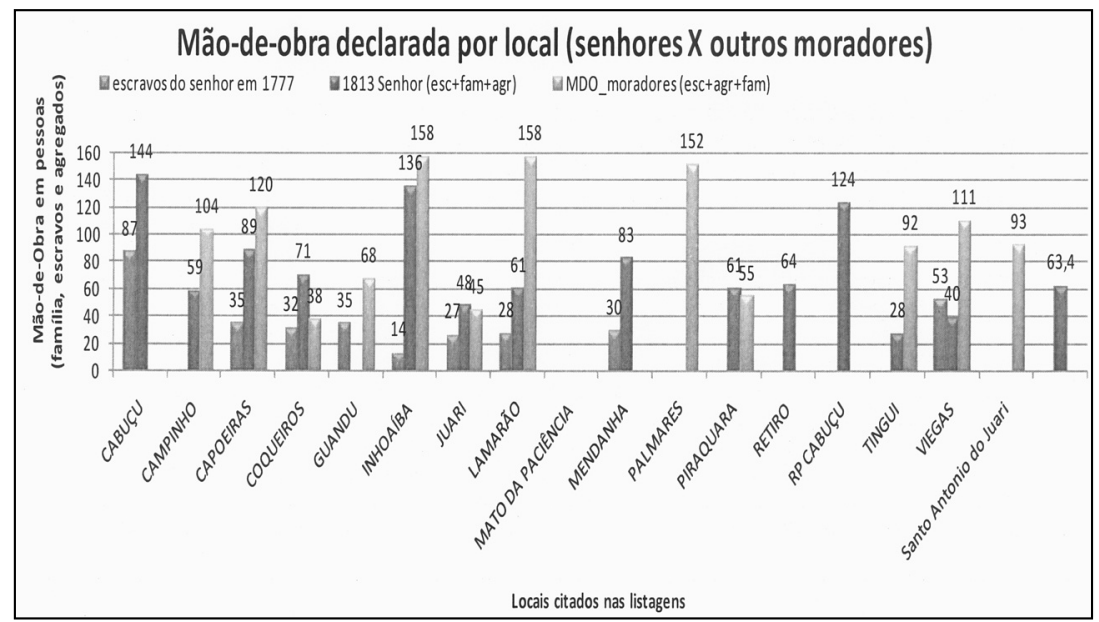

Fontes: Relatórios de 1777 e 1797, Visita Paroquial de 1794 e Desobriga de 1813. 
Mesmo que nos faltem muitas informações, o gráfico nos aponta para diferenças interessantes entre as áreas. Cruzando os dados da figura 1 (dos senhores de engenho) com o número de escravos da figura 3, podemos perceber os engenhos que pareciam bem estabelecidos, com os mesmos donos e número crescente de escravos: $\mathrm{Ca}$ poeiras, Coqueiros, Inhoaíba, Cabuçu e Rio da Prata do Cabuçu. Deste grupo, todos os que apresentam números para 1777 e 1813 tiveram crescimento de sua mão-de-obra. No outro extremo, alguns engenhos desapareceram, como o do Guandu. Próximos a esses últimos, alguns se mantiveram, mas perderam escravos e/ou mudaram muitas vezes de donos fora da família (como Viegas, ${ }^{5}$ Mendanha e Mato da Paciência). Em ambos os casos, o que vemos são estratégias distintas de fazer frente à crise econômica, ou convertendo a produção, ou convertendo o patrimônio em renda a prazo.

Mas, no meio do caminho, parte dos engenhos se manteve pequenos ou médios, não excedendo 60 escravos, convivendo ao lado de numerosas famílias de moradores livres, ou mesmo dando margem ao desenvolvimento de outras atividades econômicas, como no caso de Campinho, Juari, Lamarão e Tingüi. Esses engenhos, por sua vez, eram fábricas mais recentes de novos senhores, que não parecem ter priorizado, por diferentes motivos, o incremento da produção açucareira. $\mathrm{O}$ fato de apenas um deles ser um engenho de antiga família senhorial local (Lamarão) e os outros três fazerem parte do último grupo a ser fundado, depois de 1777, pode indicar as dificuldades de reprodução ampliada de um ciclo econômico que se esgotava, e com isso não permitia a acumulação suficiente dos que apenas dependiam de fábricas pequenas.

Nos casos em que esses moradores conviviam com um grande engenho vizinho de que temos dados, com exceção das terras de

\footnotetext{
${ }^{5}$ Detalhe importante: os dados relativos ao engenho do Viegas na Desobriga de 1813, único que apresentou mão-de-obra decrescente, podem nos confundir. Esse engenho foi seguramente comprado pelo alferes Manoel Antunes Susano em 1800 e, no seu inventário, em 1819, tinha 89 escravos. Por essa fonte, ele também se incluiria no grupo dos estáveis economicamente, mesmo que sob proprietários diversos. Cf AN. Fundo Inventários. Nome: Manoel Antunes Susano. Ano 1837. Notação 3, caixa 3629.
} 
Bangu, Coqueiros e Piraquara, em todas as outras regiões o somatório das UMO dos moradores vizinhos ao engenho é igual ou maior do que o do senhor do mesmo. E incluímos nessa conta três dos quatro engenhos dos Antunes Susano, citados anteriormente, cujas UMO haviam crescido expressivamente desde 1777. O que isso pode querer dizer? Que, além da coabitação, digamos assim, é preciso avaliar corretamente o papel desses moradores na vida econômica e social da região, para que não pareçam um 'peso morto'.

Tentaremos dialogar com o conjunto dos trabalhos da historiografia recente que tiveram por problema resgatar o papel dos homens livres e pobres na economia brasileira, sobretudo na província do Rio de Janeiro, até o século XIX. Segundo Sheila de Castro Faria,

"As análises atuais apresentam um quadro agrário bem mais diversificado, destacando a entrada, na historiografia e na sociologia, de um novo mundo, formado de sitiantes, pequenos produtores, proprietários ou não das terras que ocupavam, ou de situados, lavradores em terras alheias, relativamente autônomos dos proprietários, produtores de gêneros ou com pequenas monoculturas de café, canade-açúcar e outras (dependendo da área), que não poderiam ser definidos, e nem se autodefiniam, como senhores ou fazendeiros". (Faria, 1986, p. 222)

Para o Rio de Janeiro, pesquisas sobre os séculos XVII e XVIII fixaram o número médio de cativos por engenho em cerca de quarenta, o que coloca nossos engenhos numa média bastante confortável de 63,4 UMO. Mas a aferição da quantidade de lavradores livres que tivessem partidos de cana 'obrigados' àquele engenho seria a maneira mais correta de dimensionar sua produtividade. Em Campo Grande, havia também localidades dominadas por pequenos sitiantes provavelmente sem nenhum ou poucos escravos, fora do espectro de um engenho, como Guandu e Palmares. Mas era no continuum formado entre esses dois pólos que vivia a maior parte da população, ou seja, moradores com até quinze escravos, vizinhos a senhores-deengenho com até setenta cativos, em média.

Segundo Hebe de Mattos, os homens livres pobres eram aqueles que utilizavam poucos escravos e não tinham suas lavouras voltadas para o comércio e para a lucratividade. (Mattos, 1987, p. 82) Dedicavam-se, sobretudo ao suprimento de suas necessidades de subsistência, o que não excluía a troca em mercados locais. A defini- 
ção da autora, portanto, relaciona esses homens pobres à produção de alimentos, mas não a qualquer produção: apenas àquela em que o excedente seria trocado com o objetivo final de suprir as necessidades da unidade familiar. (Mattos, 1987)

Sobre o perfil geral dos homens livres e pobres em Campo Grande, chegamos a conclusões muito parecidas com outras pesquisas sobre a província do Rio de Janeiro: a posse de poucos escravos, estabilidade do acesso à terra (própria ou não), e produção agrícola comercial, de cana ou mandioca (Faria, 1986; Mattos, 1987; Muniz, 1979; Sampaio, 1994). Certamente nos falta a informação sobre o desenrolar de sua condição no tempo, já que temos apenas dados para o ano de 1813. Mas, ao colocarmo-los ao lado dos engenhos, no gráfico de rede, pudemos perceber que algumas regiões se caracterizavam, já naquela época, pela predominância de famílias de trabalhadores livres, independentes de um engenho, como Tingüi, Palmares, Santo Antônio de Juari e Guandu. Em outras regiões, a visível decadência ou estagnação do engenho local deu margem à proliferação de pequenas unidades familiares, como em Lamarão, Juari e Campinho. Metade eram sítios que não possuíam nenhum escravo, e a outra metade possuía uma média de 1 a 15 escravos, com poucas exceções que possuíam mais de 15 .

Embora essa média seja matematicamente verdadeira, ela novamente encobre a diversidade da condição desses moradores: encontramos desde Antônio Manoel, que declarou ter 45 escravos e 46 agregados, sem ser senhor de nenhum engenho, até as muitas famílias onde constava apenas uma viúva sem filhos. Aliás, a média encobriria até a diversidade dentro do extrato superior dos senhores, que era composto por Manoel Joaquim de Oliveira, com 130 escravos no engenho de Bangu, até Sebastião Fernandes Barata, com 18 escravos, em Piraquara.

Por esse motivo, a média, de forma geral, não nos agrada, e o leitor não vai encontrar muito esse tipo de cálculo neste trabalho. A média, sobretudo, é uma construção de fora, e a posteriori. Para os propósitos desta pesquisa, a matemática pura e desencarnada contribui pouco, pois a vida dos sujeitos - suas escolhas e seus comporta- 
mentos - definitivamente não estava predeterminada por suas características médias, e sim, pelo que chamaríamos, teleologicamente, de desvios ou de exceções à regra. Para fugir da constatação simplista de que a maior parte de uma sociedade possa ser desviante de uma regra construída centenas de anos depois que agiu, fugiremos dessa emboscada e pensaremos em outros termos.

Gostaríamos de sustentar nossa hipótese de que havia uma clivagem social bem marcada, não em torno da propriedade ou não de escravos, algo realmente bastante generalizado, nem da propriedade de terras, que sequer se aferia, mas em torno da propriedade de um engenho, mesmo que pequeno. Esse liame era o divisor de águas entre os senhores mais pobres e a ampla gama de moradores com até 15 escravos, e conferia àqueles status diferenciado destes últimos, mesmo que possuíssem igual ou menor número de escravos. Sobre os senhores de engenho se produziam enquetes, inquiria-se sua produtividade, reprovava-se sua falta de zelo, listavam-se com nomes e sobrenomes, inclusive de cônjuges e filhos. Os moradores, mesmo os mais ricos, eram apenas moradores. Dos mais pobres não se sabe nada.

Não havia uma progressão inversamente proporcional entre a pujança de um senhor e a fraqueza de seus vizinhos. Pelo contrário, mesmo que não tenhamos a informação de moradores que tenham se tornado senhores, a maioria dos engenhos da freguesia cresceu ao lado de unidades produtivas também estáveis, se não mesmo prósperas, e essas unidades, no somatório de suas forças (mesmo que esse somatório seja apenas hipotético) não podiam ser desconsideradas enquanto motores importantes da vida econômica da freguesia, embora voltadas para atividades menos lucrativas que a produção de açúcar. Nesse ponto, é preciso ter em mente que a estrutura de fornecimento da cana necessária para a produção de açúcar pressupunha uma ampla rede de lavradores livres em seus partidos, ao redor do engenho. Em outras palavras, os sítios não eram residuais em vias de extinção, nem antagônicos ao crescimento dos engenhos, mas, pelo contrário, estavam plenamente inseridos nos circuitos locais de produção e comercialização. 
Mas se a desigualdade econômica era forte e clara, com centenas de moradores com poucos escravos e poucos senhores com mais de meia centena de cativos, essas pessoas, bem ou mal, compartilhavam o mesmo espaço. Ou seja, a segregação econômica não se desdobrava em segregação espacial, com a rara exceção dos dois 'únicos donos', pois, numa mesma localidade, ou nas terras de um grande engenho, convivia ampla gama de famílias. Os sitiantes, mesmo recenseados no mesmo local em que havia agregados, quase sempre em torno de um engenho, foram citados como chefes de fogos independentes e, às vezes, possuíam escravos. Vejamos, por exemplo, o caso do engenho de Lamarão. Seu senhor, o capitão Francisco da Silva Álvares (ou Alves), possuía 65 UMO. Ao seu lado, na mesma fazenda, estava Francisco Vaz Figueira, com 35 escravos, e outras dezesseis famílias, que somavam 42 UMO. Ou seja, embora muito díspares entre si, a capacidade econômica somada dos moradores, $(35+42=77) 77 \mathrm{UMO}$, era maior do que a do senhor daquele mesmo engenho (65 UMO), mas nenhum deles trocou de posição - vendendo ou adquirindo engenhos - ao longo desse período, denotando a estabilidade dessa convivência entre desiguais.

Portanto, neste período, a dinâmica local conseguiu reproduzir endogenamente as desigualdades e hierarquias sociais, mas, por outro lado, também teve de lidar com a existência de uma ampla camada de não proprietários — os sitiantes — ligados tanto ao fornecimento de cana aos engenhos quanto à produção de gêneros de abastecimento. Como dissemos anteriormente, essa proximidade não está isenta de conseqüências, em termos sociais e políticos, o que analisaremos a seguir.

\section{Relações sociais entre a casa-grande e o mundo dos fundos}

Nesta parte, gostaríamos de explorar o fato de que a proximidade entre senhores e lavradores livres, os sitiantes, foi habilmente explorada por ambos no estabelecimento voluntário de relações pelas quais transitavam inúmeras 'reciprocidades entre desiguais'. Para conseguirmos levar em conta a qualidade, o dinamismo e o caráter estratégico dessas relações vamos analisá-las através de alguns estu- 
dos de caso, método pelo qual implicitamente rejeitamos o viés puramente quantitativo dos níveis de fortuna e também as classificações estáticas em termos de estratificação social.

Primeiramente, constatamos que a proximidade espacial e a dependência do fornecimento de cana consolidariam relações mais próximas entre lavradores e senhores de um mesmo engenho, refletidas, por exemplo, nos batizados entre seus plantéis (Pedroza, 2008). Por exemplo, a partir da década de 1740, quando o engenho de Sapopemba pertencia ao capitão João Pereira Lemos, começamos a perceber que tanto Antônio Castel Branco quanto seus filhos (todos homens livres) batizaram diretamente os filhos dos escravos de João Pereira Lemos. ${ }^{6}$ Além disso, as escravas desse capitão foram madrinhas dos filhos dos escravos dos lavradores vizinhos, dentre os quais, os de Antônio Cardoso Castel Branco. ${ }^{7}$ Como Antônio Cardoso Castel Branco, seu pai e seus filhos tinham alguns escravos, mas não consta em nossos registros que tenham sido senhores de algum engenho, julgamos que pudessem ter se especializado na plantação de cana para o engenho de Sapopemba, o que explicaria a proximidade entre seus plantéis no eito e seus conseqüentes compadrios cruzados. Agindo assim, os membros dessas famílias e suas escravarias, com algumas variações, reproduziam uma estrutura social costumeira e hierarquizada. ${ }^{8}$

Outro exemplo deste processo, mas dessa feita tecido através de compadrios de casamento e da 'doação de mulheres', foi o do lavrador Manoel Nunes de Souza. Dos seus oito filhos, quatro filhas casaram-se na capela do engenho de Sapopemba, em curto período ${ }^{9}$.

\footnotetext{
${ }^{6}$ ACMARJ, AP 343, folhas 39-verso, 33-frente, 15-verso, 2-frente, 39-verso, 33-frente, 70-frente, 75-frente, 97-verso.

${ }^{7}$ ACMARJ, AP 343, folhas 39-verso, 33-frente.

${ }^{8} \mathrm{O}$ objetivo do nosso trabalho não é a análise mais aprofundada do fenômeno do compadrio entre escravos. Para uma discussão mais bem qualificada sobre esse assunto, ver (Hameister, 2006) e (Fragoso, 2006)

${ }^{9}$ Cabe lembrar que o fato das crianças serem 'naturais da freguesia de Irajá' não permite uma localização mais precisa da residência desse casal, pois à época a freguesia compreendia os atuais bairros de Irajá e Campo Grande, Jacarepaguá, Engenho Velho, Inhaúma, Realengo, Madureira, Anchieta, Pavuna, Penha e Piedade. Cf www.ids.org.br/files/Cronologia_III.pdf e (Rheingantz, 1965)
} 
Dentre seus genros, apenas um não constou como senhor de nenhum engenho nos anos posteriores. Além disso, os novos casais foram todos apadrinhados pelo senhor de Sapopemba, padre Luis de Lemos Pereira. Dessa forma, Manoel Nunes de Souza consolidou sua posição de aliado e parente frente aos seus genros e aos senhores de Sapopemba, com os bons frutos que isso poderia render em status e mesmo em terra e trabalho. Como podemos inferir esses frutos? Bem, não sabemos onde exatamente morava Manoel Nunes de Souza à época do casamento de suas filhas (entre 1705 e 1717), mas podemos afirmar que, depois de firmados seus novos vínculos parentais, a família de origem (os pais e dois filhos) se aproximou das terras do engenho de Sapopemba, pois, na década de 1750, encontramos os escravos do padre Francisco Nunes de Souza (filho de Manoel) batizando filhos de escravos do capitão João Pereira Lemos, senhor de Sapopemba. Na mesma década de 1750, o mesmo padre Francisco Nunes de Souza batizou dois dos filhos do capitão João Pereira Lemos, o que demonstra sua crescente intimidade ${ }^{10}$.

Entende-se comumente que compadrios de uma mesma família abastada, direcionados para outras famílias de diferentes estratos sociais, foram uma das estratégias das elites para a criação de redes clientelares e para a demonstração do seu prestígio. Não esqueçamos que a qualidade dos senhores se mostrava, também, pela amplitude de sua rede clientelar e nas várias possibilidades que tinham de teatralizar sua generosidade para com parentes, afilhados e protegidos. Mas será que essa relação seria estratégica apenas para cimentar a dominação?

Achamos que não. Por exemplo, Luiz Antunes Susano, lavrador livre e pobre, casou-se apadrinhado pelo senhor da Fazenda das Capoeiras, capitão José Antunes Susano, seu primo, em 1797, esta-

\footnotetext{
${ }^{10} \mathrm{Na}$ década de 1740, um padre chamado Francisco Nunes de Souza apareceu como proprietário de ao menos dez escravos nos registros de batismo de escravos de Irajá. Ele seria filho de Manoel Nunes de Souza, batizado em 1693. Cf (Rheingantz, 1965, p. 107 a 114, Tomo II); ACMARJ. Livro de registro de batismos de livres, Freguesia de Campo Grande, p. 59-frente; ACMARJ, AP 343, folhas 52-frente, 27-verso, 80-verso, 89-verso, 107-verso, 105-frente; e Livro de Batismo de Livres de Irajá, folhas 94-frente e 106-frente.
} 
belecendo-se como sitiante dentro dessa fazenda (Rheingantz, 1965). Luiz Antunes Susano chegou a ser tenente, mas não tinha terras, apenas o direito a um pequeno sítio de 49 braças. Portanto, os seus filhos dependeriam dos contatos com a parte senhorial da parentela para ter acesso à terra de trabalho, se quisessem se estabelecer no local. Em nossa opinião, não por outro motivo o tenente Luiz deu o seu filho mais velho para ser batizado pelo capitão José Antunes Susano, com o mesmo nome dele. Esse filho sempre trabalhou no engenho de Inhoaíba, como pessoa de confiança do padrinho. Outro filho trabalhava em um engenho vizinho, até ser convidado pelo tio capitão para administrar outro de seus engenhos, na distante freguesia de Itacuruçá, para onde se mudou. Morreu solteiro.

No fim da vida desses primos, tenente Luiz e capitão José, quase como um coroamento por tanta proximidade e fidelidade, o capitão José escolheu como terceira esposa a segunda filha de Luiz, com a qual teve um filho. Portanto, ao morrer o capitão José Antunes Susano, em 1827, além de Luiz ter dois outros filhos como administradores de engenhos do falecido, ele era ainda tutor do neto e pai da viúva. Provavelmente por isso ele assumiu total ou em parte a gerência do engenho de Inhoaíba. Esse caso, ao lado de alguns outros analisados em outro trabalho (Pedroza, 2008), faz com que defendamos a hipótese de que 'casamentos desiguais' e trocas de 'esposas pobres' não traziam conforto material apenas para a 'moça pobre' felizarda. Toda sua família de origem se beneficiava em algum grau por fazer parte, mesmo de maneira subordinada, de uma rede de parentela senhorial. Esse benefício pode ser lido, por exemplo, na estabilidade adquirida pelos segmentos de sitiantes nas franjas das terras dos engenhos, ou mesmo na transferência do engenho em si para um antigo lavrador sem posses, como foi o caso do engenho do Viegas, que analisamos em outro trabalho (Pedroza, em avaliação).

Outras famílias pobres vizinhas, mesmo não aparentadas, também tentavam se aproximar da casa-grande: davam seus filhos para serem batizados pelo senhor, batizavam eles mesmos seus escravos, aproveitavam as oportunidades de casar suas moças com membros menos cotados para a sucessão senhorial e, com sorte, paciência e 
bons serviços, manteriam os partidos de cana e as casas velhas construídas em terras de outrem, mas necessárias ao funcionamento do engenho. No pior dos cenários, esses lavradores pobres herdariam o direito de uso das terras que não lhes pertenciam, mas que tradicionalmente lhes davam o estatuto de sitiantes nas fazendas de seus parentes ou compadres (Pedroza, 2009). Tendo alguma sorte, seriam afilhados dos últimos, o que lhes aumentaria a possibilidade de ter um melhor casamento, trabalho e legados. Com mais sorte, poderiam desdobrar a proximidade no mundo do trabalho em confiança mútua, através da qual os lavradores saíam de seus arrendamentos, partidos e sítios e galgavam postos na gerência ou mesmo na administração direta do patrimônio senhorial.

\section{Conclusão}

Esperamos ter demonstrado satisfatoriamente que nos fundos de um engenho de açúcar no Recôncavo da Guanabara, desde meados do século XVIII, convivia ampla gama de famílias de lavradores livres e pobres, cuja capacidade produtiva fazia diferença na economia desses engenhos, mesmo num modo de produção marcadamente escravista. Dando um passo adiante e aceitando o desafio proposto por Marx de entender a lógica do modo de produção (em nosso caso, do 'modo de produção escravista colonial' (Cardoso, 1980)) dentro da especificidade histórica e da ação humana (Wood, 2003, p. 59), descobrimos que as redes sociais da freguesia partiam de constrangimentos bastante concretos, financeiros, agrários, étnicos e culturais, mas acabaram por amarrar entre si famílias senhoriais e pobres sitiantes, através de uma dinâmica social particular que criava pontes entre o mundo do trabalho, da terra e da parentela.

Podemos dizer que a empresa colonizadora na freguesia de Campo Grande se fez como construção e expansão de 'redes densas' (Barnes, 1969) que sobrepunham relações de reciprocidade desiguais intra e entre parentelas (sangüínea, por casamento e ritual) às relações de produção (senhores estabelecidos, futuros senhores, sitiantes e seus escravos). Assim, dentro das possibilidades daquela estru- 
tura sócio-econômica, foram gestadas práticas e relações sociais originais, de caráter voluntário e estratégico para os pólos envolvidos nesse jogo - senhores e lavradores livres -, criando uma dinâmica própria que nos parece compor a cultura política típica do 'Antigo Regime nos Trópicos' (Fragoso, 2001), ou, ao menos, a forma específica com que esse também circulou e foi operacionalizado pelas mentes e corações dos estratos livres e pobres da colônia.

Não custa reforçar que acreditamos que a estabilidade de sitiantes em terras de outrem, sua convivência com os senhores de engenhos parentes e vizinhos, e mesmo a ascensão sócio-econômica de alguns, tenham sido uma construção tática deles próprios. Se esses grupos sociais apenas reproduzissem os esquemas hierárquicos que lhes eram atribuídos, perpetuariam a exploração e acumulação nas esferas econômicas e mercantis (no caso, o agro dos engenhos de açúcar), referendados, ou amaciados, por contradons, legados e benesses em outros planos, como o religioso ou o social. Diferente disso, o que vimos esboçado na Desobriga de 1813 foi um mosaico de sítios, datas, partidos, engenhos, fazendas, situações e sesmarias, de diversos tamanhos, capacidades produtivas e histórias, frutos de arranjos sociais originais e dificilmente previsíveis.

\section{BIBLIOGRAFIA}

Barnes, J. A. Networks and Political Process. In: Mitchell, J. Clyde (Org.). Social Networks in urban situations. Manchester: Manchester University Press, 1969.

Barth, Fredrik. O guru, o iniciador e outras variações antropológicas. [Tradução de Comerford, John Cunha). Rio de Janeiro: Contracapa, 2000. (Typographos). $243 \mathrm{p}$.

Cardoso, Ciro F. . As concepções acerca do Sistema Econômico Mundial e do Antigo Sistema Colonial: a preocupação obsessiva com a Extração de Excedente. In: Lapa, José R. do Amaral (org) (Org.). Modos de produção e realidade brasileira. Petrópolis: Vozes, 1980.

Chayanov, Alexander. The theory of peasant economy. Homewood, Illinois: Richard D Irwin Inc, 1966 [1924]. 
Costa, Iraci. Notas sobre a posse de escravos nos engenhos e engenhocas fluminenses (1778). Revista do Instituto de Estudos Brasileiros. n. 28, 1988. Faria, Sheila Siqueira de Castro. Terra e Trabalho em Campos dos Goitacazes (1850-1920). 1986. Niterói. Dissertação de mestrado. (PPG História) - UFF.

Fragoso, João Luís Ribeiro A nobreza da República: notas sobre a formação da primeira elite senhorial do Rio de Janeiro (séculos XVI e XVII). TOPOI: Revista de História do Programa de Pós-Graduação em História Social da UFRJ. Sete Letras, vol. 1, 2000.

Fragoso, João Luís Ribeiro Para que serve a história econômica. Estudos Históricos. Rio de Janeiro, vol. 29, 2002.

Fragoso, João Luís Ribeiro Principais da terra, escravos e a república: o desenho da paisagem agrária do Rio de Janeiro seiscentista. Ciência e Ambiente. Santa Maria, RS, vol. 33, 2006.

Fragoso, João; Bicalho, Maria Fernanda Baptista; Gouvêa, Maria de Fátima Silva (orgs). O Antigo Regime nos Trópicos: a dinâmica imperial portuguesa (séculos XVI-XVIII). Rio de Janeiro: Civilização Brasileira, 2001. $473 \mathrm{p}$.

Fragoso, João; Florentino, Manolo. $O$ arcaísmo como projeto: mercado atlântico, sociedade agrária e elite mercantil no Rio de Janeiro (1790-1840). $2^{\mathrm{a}}$ ed. Rio de Janeiro: Sette Letras, 1996. 117 p.

Fróes, Jose Nazareth de Sousa e Gelabert, Odaléa Ranauro Ensenat. Rumo ao Campo Grande: por trilhas e caminhos. Rio de Janeiro: sem editora, 2004. 247 p.

Hameister, Martha Daisson. Para dar calor à nova povoação: estudo sobre estratégias sociais e familiares a partir dos registros batismais da vila do Rio Grande (1738-63). 2006. Rio de Janeiro. Tese de doutorado. (PPG História) - UFRJ.

Lamego, Alberto Ribeiro. Os engenhos de açúcar nos recôncavos do Rio de Janeiro, em fins do século XVII. Brasil Açucareiro. 1942.

Levi, Giovanni. Centro e periferia di uno stato assoluto: tre saggi su Piemònte e Liguria in età moderna. Torino: Rosenberg and Sellier, 1981.

Levi, Giovanni. Reciprocidad mediterránea. Tiempos Modernos: Revista Electrónica de Historia Moderna. n. 7, 2002.

Levi, Giovanni. Un problema de escala. Relaciones: Revista de El Colegio de Michoacán. Zamora, México, vol. 24, n. 95, p. 279-288, 2003. 
Mattos, Hebe Maria. Ao Sul da História: lavradores pobres na crise do escravismo. São Paulo: Brasiliense, 1987.

Muniz, Célia Maria Loureiro. Os donos da terra: um estudo sobre a estrutura fundiária do Vale do Paraíba Fluminense no século XIX. 1979. Niterói. Dissertação de Mestrado. (PPG História) - UFF.

Pedroza, Manoela. Capitães de bibocas: casamentos e compadrios construindo redes sociais originais nos sertões cariocas (Capela de Sapopemba, freguesia de Irajá, século XVIII). Topoi: Revista do Programa de PósGraduação em História da UFRJ. Rio de Janeiro, RJ, Brasil: UFRJ, vol. 9, n. 17, p. 67-92, 2008.

Pedroza, Manoela. Passa-se uma engenhoca: ou como se faziam transações com terras, engenhos e crédito em mercados locais e imperfeitos (freguesia de Campo Grande, século XVIII-XIX). Varia Historia: Revista do Departamento de História da UFMG. Belo Horizonte, MG, Brasil: UFMG, em avaliação.

Pedroza, Manoela. Transmissão de terras e direitos de propriedade desiguais nas freguesias de Irajá e Campo Grande (Rio de Janeiro, 1740-1856) Revista de História. São Paulo: USP, n. 160, 2009.

Rheingantz, Carlos Grandmasson. Primeiras Famílias do Rio de Janeiro. Rio de Janeiro: Livraria Brasiliana, 1965.

Sampaio, Antonio Carlos Jucá de. Na encruzilhada do império: hierarquias sociais e conjunturas econômicas no Rio de Janeiro (1650-1750). Rio de Janeiro: Arquivo Nacional, 2003. 342 p.

Sampaio, Antônio Carlos Jucá de. Magé na crise do escravismo: sistema agrário e evolução econômica (1850-1888). 1994. Niterói. Dissertação de mestrado. (PPG História) - UFF.

Várzea, Affonso. Engenhos dentre Guanabara-Sepetiba. Brasil Açucareiro. 1945.

Wood, Ellen Meiksins. Democracia contra capitalismo: a renovação do materialismo histórico. São Paulo: Boitempo, 2003.

Recebido em 03 de abril de 2009. Aprovado em 26 de outubro de 2009. 